\title{
Sensitive detection of tumour cells in effusions by combining cytology and fluorescence in situ hybridisation (FISH)
}

\author{
M FiegI ${ }^{*, 1}$, A Massoner', M Haun', W Sturm², H Kaufmann ${ }^{3}$, R Hack $^{4}$, J Krugmann ${ }^{5}$, M Fritzer-Szekeres ${ }^{6}$, \\ K Grünewald' and G Gastl'
}

'Division of Haematology and Oncology, Department of Internal Medicine, Medical University of Innsbruck, Innsbruck, Austria; ${ }^{2}$ Division of General Internal Medicine, Department of Internal Medicine, Medical University of Innsbruck, Innsbruck, Austria; ${ }^{3}$ Department of Internal Medicine I, Division of Oncology, Medical University of Vienna, Vienna, Austria; ${ }^{4}$ Department of Pulmonology, Krankenhaus Natters, Natters/Tyrol, Austria; ${ }^{5}$ Institute of Pathology, Medical University of Innsbruck, Innsbruck, Austria; ${ }^{6}$ Clinical Institute of Medical and Chemical Laboratory Diagnostics, Medical University of Vienna, Vienna, Austria

Diagnosis of malignant cells in effusions is important for staging procedures and resulting therapeutic decisions. Cytodiagnostics in effusions is sometimes difficult since reactive mesothelial cells can mimic malignant cells. We used fluorescence in situ hybridisation (FISH) in single-colour or if appropriate in dual-colour evaluation to detect chromosomal aberrations in effusion cells as markers of malignancy, to raise the diagnostic yield. Cytologic and FISH evaluations - by using probes representing several chromosomes always including chromosomes II and 17 - were performed in 358 effusion fluids. Cytology was positive for malignancy in 44.4\% of all effusions, whereas FISH was positive in $53.9 \%(P=0.000 \mathrm{I})$. The combination of cytology and FISH was diagnostic for malignancy in $60.9 \%$ of effusions. Diagnostic superiority of FISH was demonstrated in effusions from breast cancer, lung cancer, pancreatic cancer, and in effusions from the entire group of gynaecological and gastrointestinal carcinomas. In transudates (effusion protein $<2.5 \mathrm{~g} \mathrm{dl}^{-1}$ ), malignant cells were detectable by cytology, FISH, and combined use of both methods in 18.6, 30, and 37.1\% of effusions, respectively, suggesting that cytologic and molecular analysis should be performed also with transudates. In conclusion, FISH in combination with conventional cytology is a highly sensitive and specific diagnostic tool for detecting malignant cells in effusions. British Journal of Cancer (2004) 91, 558-563. doi: I0.1038/sj.bjc.6601942 www.bjcancer.com

Published online 29 June 2004

(c) 2004 Cancer Research UK

Keywords: malignant effusion; FISH; cytology; aneuploidy; transudate; molecular staging

Effusion fluids in cancer patients can arise in the pleural, pericardial, and peritoneal space. Pathologic accumulation of such fluid is driven by different forces, among which are 'paraneoplastic' effects triggered directly or indirectly by tumour cells. For example, vascular endothelial growth factor (VEGF) can be released from tumour cells and it increases the permeability of peritoneal microvessels and thus contributes to effusion accumulation. On the other hand, removal of VEGF from the peritoneal cavity has been shown to inhibit ascites formation in ovarian cancer models (Byrne et al, 2003). About 10-15\% of all effusions submitted for pathological analysis are tumour-associated (Runyon, 1994; Light, 2002), and about $50 \%$ of patients develop an effusion at some time during the course of disease. Clinically, effusion in tumour disease heralds local disease progression, relapse or metastasis (Raju and Kardinal, 1981). However, pleural or ascitic effusions do not always indicate advanced or metastatic malignant disease, with major clinical consequences. For example, in lung cancer, a cytologically negative effusion at primary

\footnotetext{
* Correspondence: Dr M Fiegl, Department of Internal Medicine, Natters Hospital, In der Stille 20, A-6I6I Natters, Austria;

E-mail: michael.fieg|@uibk.ac.at

Received 5 February 2004; revised 26 April 2004; accepted 27 April 2004; published online 29 June 2004
}

diagnostic workup usually corresponds with a limited disease stage, whereas a cytologically positive pleural effusion represents a UICC/AJCC TNM stage T4 (TNM classification, 1997), translating into inoperable stage IIIB or IV disease. It is well documented that the quality of cytodiagnostics regarding tumour-associated effusions primarily depends on the investigator's experience to discriminate malignant from reactive effusions. The diagnosis of malignancy in effusions can be troublesome due to the cellular composition of effusions. The occurrence of single or clustered 'activated mesothelial cells' with morphological features of tumour cells can mimic malignancy (Koss, 1992). On the other hand, in effusions tumour cells may appear quite similar to normal cells, for example, small-cell lung cancer cells and lymphocytes (Chhieng et al, 2001). Due to these difficulties, cytopathologists traditionally adopt a rather cautious approach in the diagnosis of malignancy in effusions. In fact, the sensitivity for the cytological diagnosis of malignant cells in effusions even in patients with known cancer is astonishingly low, that is, about 50\% (reviewed in Fiegl et al, 2003). Moreover, the specificity of cytological analysis in effusions does not reach $100 \%$. Falsely positive results in effusions may occur due to chronic irritating states of different kinds (Kutty et al, 1981; Guzman et al, 1992). Thus, new diagnostic approaches are warranted to enhance the sensitivity and specificity of tumour cell detection in effusions. We and others used fluorescence in situ hybridisation (FISH) to sensitively detect tumour cells regularly 
characterised by numeric chromosomal aberrations (Fiegl et al, 2000, 2004; van Oostenbrugge et al, 2000). By identification of tumour-associated aneuploidy, FISH analysis has been successfully applied in tumour aspirates, urine, cerebrospinal fluid, cervical smears, sputum, and effusions (Cajulis et al, 1994; Chen et al, 1995; Ichikawa et al, 1996; Schenk et al, 1997; Mian et al, 1999; Fiegl et al, 2000, 2004; van Oostenbrugge et al, 2000).

The aims of this study were (1) to determine the percentage of effusions, which is the first manifestation of malignant disease and of relapse, (2) to test the diagnostic power of FISH as compared to cytology in effusions taken from different tumour entities, and (3) to compare the sensitivity of cytology and FISH in transudates. The study presented here includes an updated series of 358 effusion specimens, of which various cytological and molecular aspects have already been previously published (Fiegl et al, 2000, 2004).

\section{MATERIALS AND METHODS}

\section{Effusion samples}

In all, 403 effusion specimens were collected consecutively from 301 patients with various carcinomas. A total of 110 effusions originated from patients who had two or three repeated effusion punctures. Further, 45 of the effusion samples were excluded from analysis since the time interval between sample collections in an individual patient was less than 1 month, and, therefore, a significant alteration of cellular composition could not be expected. Thus, a total of 358 effusion fluids (198 of pleural, 153 of ascitic origin, five lavage, and two cyst fluids) were subjected to FISH analysis using centromeric probes for 2-6 chromosomes. An aliquot of $20-50 \mathrm{ml}$ of each effusion was submitted to the Department of Pathology for cytological evaluation after routine staining (Giemsa, Papanicolau, or H\&E). The first 201 effusions (series 1; Fiegl et al, 2000) were analysed at the University of Vienna Medical School between 1994 and 1998, whereas the remaining 157 effusions (series 2; Fiegl et al, 2004) were analysed at the University of Innsbruck Medical School between 2001 and 2002. For the definition of cutoffs for malignancy by FISH analysis (Table 2), cells from 15 and 66 control effusions, derived from patients with diseases other than cancer, were used in series 1 and 2 , respectively.

A detailed description of the progeny of effusions, their underlying malignancies, and the proportion of effusions occurring as the first manifestation of malignant disease or of relapse is given in Table 1. All patients had former or present histopathologically or cytologically verified tumours, mostly with distant metastasis or locally advanced, inoperable disease.

\section{Fluorescence in situ hybridisation analysis}

Cells of at least $350 \mathrm{ml}$ of effusion fluid (exception: lavages, cyst fluids, and a few effusions with $2-100 \mathrm{ml}$ obtained) were gained by centrifugation, and, in case of macroscopic blood contamination, subjected to density gradient separation over Ficoll-Hypaque (Sigma, St Louis, MO, USA). Pelleted effusion cells were washed in phosphate-buffered saline, fixed in methanol-acetic acid $(3: 1$, $\mathrm{vv}^{-1}$ ) and stored at $-80^{\circ} \mathrm{C}$. Directly fluorescence-labelled alphasatellite DNA probes (SpectrumGreen ([excitation peak of $497 \mathrm{~nm}$, emission peak of $524 \mathrm{~nm})$ and SpectrumOrange $(559 / 588 \mathrm{~nm}$ ); Vysis Inc, Downers Grove, IL, USA) were applied in dual-colour FISH experiments. The probes used in this study were specific for the centromeres of chromosomes $7,8,11,12,17$, and 18 for the first 201 consecutive effusions (Fiegl et al, 2000); subsequently, only probes representing chromosomes 11 and 17 were used (Fiegl et al, 2004). The standard protocol followed has been described in a previous report, with minor modifications (Drach et al, 1995).
Table I Origin of effusions, underlying malignancies and number of effusions representing first manifestation of disease or of relapse

\begin{tabular}{|c|c|c|c|c|c|}
\hline \multirow[b]{2}{*}{$\begin{array}{l}\text { Tumour } \\
\text { entity }\end{array}$} & \multirow[b]{2}{*}{$\begin{array}{c}\text { Patients } \\
\text { (n) }\end{array}$} & \multirow[b]{2}{*}{$\begin{array}{c}\text { Effusions } \\
\text { (n) }\end{array}$} & \multirow[b]{2}{*}{$\mathbf{A} / \mathbf{P} / \mathbf{L} / \mathbf{C}^{\mathbf{a}}$} & \multicolumn{2}{|c|}{ Effusion } \\
\hline & & & & $\begin{array}{c}\text { First } \\
\text { manifestation } \\
\text { of disease }\end{array}$ & $\begin{array}{c}\text { First } \\
\text { manifestation } \\
\text { of relapse }\end{array}$ \\
\hline Breast & 77 & 104 & $28 / 75 / 0 / 1$ & 4 & 24 \\
\hline Lung & 60 & 71 & $7 / 64$ & 21 & 7 \\
\hline Pancreatic & 33 & 34 & $31 / 3$ & I & 1 \\
\hline Ovarian & 26 & 29 & $|8 / 9 /| / \mid$ & 10 & 2 \\
\hline Hepatoma & 17 & 17 & $15 / 2$ & & \\
\hline$U P C^{a}$ & 13 & 17 & $14 / 3$ & 5 & \\
\hline Gastric & 12 & 14 & $13 / 1$ & 2 & । \\
\hline Colorectal & 11 & | | & $7 / 4$ & & \\
\hline Endometrial & 9 & 11 & $4 / 3 / 4$ & I & 4 \\
\hline Cholangio-cellular & 8 & 9 & $9 / 0$ & I & \\
\hline Renal & 8 & 9 & $4 / 5$ & & 2 \\
\hline Haematological & 9 & 10 & $2 / 8$ & & \\
\hline Mesothelioma & 3 & 4 & $1 / 3$ & I & \\
\hline Cervical & 3 & 3 & $2 / 1$ & 0 & । \\
\hline Others & 12 & 15 & $1 / 14$ & & 2 \\
\hline Sum & 301 & 358 & |56/195/5/2 & 46 & 44 \\
\hline
\end{tabular}

${ }^{a} A=$ ascites; $P=$ pleural effusion; $L=$ lavage fluid; $C=$ cyst fluid; $U P C=$ unknown primary cancer.

\section{Fluorescence microscopy and definition of cutoffs for aneuploidy}

A fluorescence microscope with $\times 60$ and $\times 100$ planar objectives and appropriate filter sets was used for FISH signal evaluation and documentation. All effusion cells in a field except for polynucleated granulocytes, which are easily distinguishable by nuclear shape, were analysed. The stringent criteria of FISH signal assessment were applied to avoid overestimation of hyperdiploidy, which may result from cellular and technical factors (reviewed in Eastmond et al, 1995). Signal counting was performed by two investigators, and intraobserver and interobserver counting variations were evaluated repeatedly. In order to evaluate the frequencies of aneusomic effusion cells with statistical reliability, centromeric signals of 100-1000 nuclei were scored, with highnumber cell counting in samples with a low frequency of aneuploidy (Kibbelaar et al, 1993). When necessary, we used a two-tiered scoring procedure: (1) in all 358 effusions, scoring of nuclei in single-colour FISH evaluation was performed, and if aneusomy above cutoff for any of the tested chromosomes (Table 2) was present, malignancy could be documented; otherwise, in step (2), scoring of selected, namely hyperdisomic, nuclei was performed in dual-colour FISH evaluation, which allowed for the detection of rare FISH-aneuploid cells (Fiegl et al, 1999). For the analysis of the first 201 effusions (series 1) and the remaining 157 effusions (series 2), slightly different criteria to discriminate malignant from reactive effusions by FISH were used. This was necessary since the first author changed laboratories in 1998 and, therefore, cutoffs for background aneusomy and true, tumour-associated aneuploidy had to be redefined. In Table 2, the criteria which allowed diagnosis of malignant cell involvement in effusion series 1 and 2 are presented, and the diagnostic specificities as determined in control effusions are indicated. In series 1, cutoffs (Table 3 ) were derived from the analysis of a somewhat limited number of 15 control effusions, whereas the slightly more stringent cutoffs used in series 2 were derived from 66 control effusions; we concluded that the specificity of FISH evaluation was at least 97\% (Fiegl et al, 2004).

All test effusion specimens were routinely evaluated by cytology and classified as being benign/reactive or malignant using 
Table 2 Definition of criteria which enabled the diagnosis of tumour-associated aneuploidy by FISHa in a two-step microscopic evaluation of effusion specimens

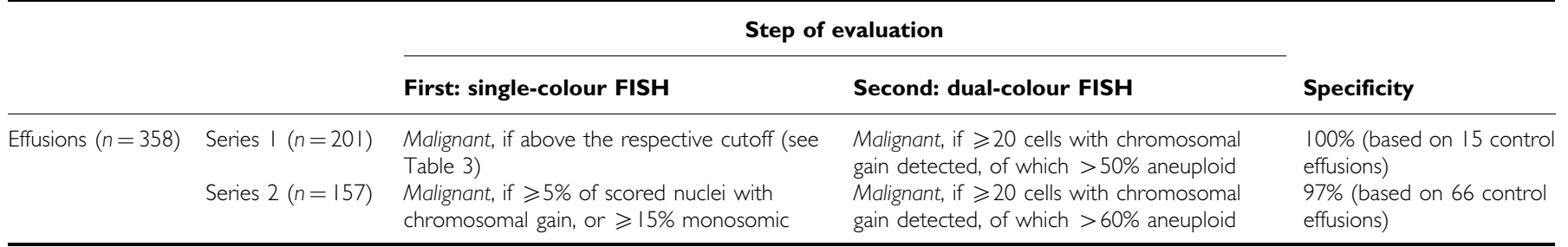

${ }^{a}$ Between series I and series 2, the cutoffs in single-colour and dual-colour FISH evaluation differed, as indicated in the table. Briefly, in the first step of evaluation, nuclei in an effusion were evaluated in single-colour evaluation, and, if the percentage of nuclei was above cutoff for any of the evaluated chromosomes, a diagnosis positive for malignant cell involvement was given. If the diagnosis was negative, the second step of evaluation in dual-colour FISH evaluation followed: upon screening of about I0 $000-20000$ nuclei, only nuclei with hyperdisomy were recorded; those with concordant signal gain (e.g., 4/4-pattern) were classified as polyploid, whereas those with discordant signal gain (e.g., 3/5pattern) were classified as aneuploid. Aneuploidy above cutoff as indicated in the table was diagnostic for malignancy (also detailed in Fiegl et al, 2000, 2004).

Table 3 Cutoff threshold levels for background aneusomy (percentage) for the six chromosomes examined in series I (1994-1998)

\begin{tabular}{lrrrr}
\hline & \multicolumn{4}{c}{ Signal number category } \\
\cline { 2 - 5 } & $\mathbf{I}$ & $\mathbf{3}$ & $\mathbf{4}$ & $>\mathbf{4}$ \\
\hline Chromosome 7 & 11.5 & 0.6 & 0.7 & 0.2 \\
Chromosome 8 & 8.7 & 0.5 & 0.9 & 0.1 \\
Chromosome 11 & 11.2 & 0.4 & 1.2 & 0.2 \\
Chromosome 12 & 10.0 & 1.4 & 1.0 & 0.2 \\
Chromosome 17 & 13.4 & 0.9 & 1.0 & 0.1 \\
Chromosome 18 & 14.7 & 0.6 & 0.7 & 0.0 \\
\hline
\end{tabular}

The presented cutoffs were determined by evaluation of non-disomy in 15 nonmalignant control effusions, and reflect the mean +3 s.d. percentage of aneusomic cells within each of four FISH signal categories (see Fiegl et al, 2000).

generally accepted criteria (Koss, 1992). Malignancy was also assumed when only a few suspicious cells (single or clustered) were present (Sears and Hajdu, 1987). Cytologic evaluation in all 81 control effusions was positive for malignancy in four cases; thus, the resulting specificity for cytology was $95 \%$.

\section{Statistical analysis}

McNemar's test was used to compare the two different analytical methods within the one given sample cohort of 358 effusions (Dwyer, 1991). SSPS software was used for calculations.

\section{RESULTS}

\section{Patients' characteristics}

In total, 358 effusions were derived from 301 patients with histologically proven tumour disease. The most frequent underlying tumour entities were breast, lung, pancreatic, ovarian, and hepatocellular cancer (Table 1). Included in this series were also a few patients who suffered previously from a tumour and developed an effusion of unknown origin later in life. Effusion development was the primary manifestation of malignancy in 46 out of 301 patients (15.3\%). A malignant effusion appeared as the first disease manifestation in 10 out of 26 cases with ovarian cancer $(38.4 \%)$ and in 21 out of 60 cases (35\%) with lung cancer. Effusion was the first and frequently the single sign of relapse in 44 out of 301 patients (14.6\%). This was most often noted in patients with breast cancer (24 out of $67,35.8 \%$ ). Detailed frequencies of effusion as the first sign of disease or relapse according to tumour entities are listed in Table 1.

\section{Fluorescence in situ hybridisation for detection of tumour- associated aneuploidy}

Fluorescence in situ hybridisation analysis was performed in single-colour FISH evaluation when aneusomy was present above a cutoff value, unambiguously discriminating tumour-associated aneusomy from background 'physiological' aneusomy. When aneusomic cells were rare, evaluation in dual-colour FISH evaluation was performed aiming at discriminating polyploidy from aneuploidy originating from tumour cells (Figure 1). The data presented in this paper represent two compiled series of effusions analysed in two different laboratories. Slightly different cutoffs for the diagnosis of true malignancy by single- or dualcolour FISH were applied (Table 2). The larger series presented here enabled us to test the diagnostic utility of FISH in different tumour entities. Fluorescence in situ hybridisation analysis was diagnostic for malignant cells in 193 out of 358 effusions (53.9\%), whereas cytologic evaluation was positive in 159 out of 358 (44.4\%). This difference in favour of FISH was statistically significant $(P=0.0001$; McNemar's test). Taking the positive results of cytology and FISH together (cyto\&FISH), the overall diagnostic yield was $60.9 \%$ (malignancy in 218 out of 358 effusions). Next, the contribution of FISH to detect malignancy in different tumour entities and tumour categories was analysed, and the results are summarised in Table 4. Briefly, FISH was significantly superior as compared to cytology in effusions from breast carcinoma, lung carcinoma, and gynaecological malignancies as a whole category. When the sensitivity of overall cyto\&FISH was compared to that of cytology alone, the combined diagnostic workup yielded a significantly superior sensitivity for effusions from pancreatic carcinoma and all gastrointestinal tumours together.

In all, 17 effusions originated from patients who formerly suffered from malignancy but were free from manifest malignant disease at the time of puncture or thereafter. These patients had had hepatoma $(n=8)$, breast cancer $(n=3)$, renal, endometrial, cholangiocellular, bronchial carcinoma ( $n=1$ each), carcinoma of the cervix uteri $(n=1)$, and chronic myelogeneous leukaemia $(n=1)$. None of these effusions was classified as malignant by cytology or FISH; thus, they were viewed as of reactive cause.

\section{Cytology and FISH evaluation in transudates}

In the following section, the sensitivity of cytology, FISH, and the combined evaluation was compared between exsudates and transudates. Results are presented in Table 5. Two different definitions to discriminate exsudates from transudates were applied: a transudate was defined by (i) a protein concentration of $<2.5 \mathrm{~g} \mathrm{dl}^{-1}$ (Runyon et al, 1992), (ii) an effusion/serum protein gradient of $<0.5$ (Light, 2002). 
Table 4 Diagnostic sensitivities of cytology, FISH, and the combination of both (cyto\&FISH) in the whole series of effusions and major tumour entities (with $\geqslant 10$ effusions per tumour entity available)

\begin{tabular}{|c|c|c|c|c|c|c|}
\hline Tumour & Effusion (n) & Sensitivity cytology (\%) & Sensitivity FISH (\%) & $P$ & Sensitivity Cyto\&FISH (\%) & $P$ \\
\hline All & 358 & 44.4 & 53.9 & 0.0001 & 60.9 & 0.0001 \\
\hline Gynaecologic $^{a}$ & 147 & 54.4 & 63.9 & 0.018 & 72.1 & 0.0001 \\
\hline Breast & 104 & 50 & 63.1 & 0.031 & 71.2 & 0.0001 \\
\hline Ovarian & 29 & 65.5 & 72.4 & 0.727 & 82.75 & 0.063 \\
\hline Endometrial & $1 \mid$ & 54.4 & 63.6 & I & 63.6 & । \\
\hline Gastrointestinal $^{\mathrm{b}}$ & 87 & 28.7 & 36.8 & 0.118 & 41.4 & 0.001 \\
\hline Pancreatic & 34 & 38.2 & 52.9 & 0.125 & 55.9 & 0.031 \\
\hline Hepatoma & 17 & 0 & 5.9 & I & 5.9 & I \\
\hline Gastric & 14 & 50 & 64.3 & 0.625 & 71.4 & 0.25 \\
\hline Colorectal & | | & 18.2 & 18.2 & 1 & 27.3 & 1 \\
\hline Lung & 71 & 54.9 & 71.8 & 0.008 & 76.1 & 0.0001 \\
\hline$U^{\prime} C^{c}$ & 17 & 35.3 & 47.1 & 0.687 & 58.8 & 0.125 \\
\hline Haematological $^{d}$ & 10 & 50 & 30 & 0.5 & 50 & I \\
\hline
\end{tabular}

The $P$-values indicate significance levels for the comparison of FISH vs cytology (left column) and of cyto\&FISH vs cytology (right column). ${ }^{a}$ Gynaecologic tumours: breast ( $n=$ 104), ovarian (29), endometrial (I I), and cervical carcinoma (3). ${ }^{b}$ Gastrointestinal tumours: pancreatic (34), hepatocellular ( I ), gastric ( I4), colorectal (I I), cholangiocellular (9), and oesophageal carcinoma (2). 'UPC, unknown primary cancer. 'Haematological malignancies: non-Hodgkin's lymphoma (5), chronic myelogeneous leukaemia (2), Hodgkin's lymphoma (2), idiopathic myelofibrosis (I).

Table 5 Diagnostic sensitivity of cytology and FISH (and their combination) in transudates ${ }^{a}$

\begin{tabular}{|c|c|c|c|c|}
\hline & & \multicolumn{3}{|c|}{ Number of transudates positive for tumour cells (\%) } \\
\hline Definition transudate & $\begin{array}{l}\text { Protein }<2.5 \mathrm{~g} \mathrm{dl}^{-1}(n=70) \\
\text { Effusion/serum-protein gradient }<0.5(n=60)\end{array}$ & $\begin{array}{l}13(18.6) \\
21(35)\end{array}$ & $\begin{array}{l}21(30) \\
24(40)\end{array}$ & $\begin{array}{l}26(37.1) \\
30(50)\end{array}$ \\
\hline
\end{tabular}

${ }^{a}$ Two different common definitions, as explained in the text.

In all, 70 of the 243 effusions for which the protein concentration was available were diagnosed as transudates due to a protein concentration $<2.5 \mathrm{~g} \mathrm{dl}^{-1}$; in these samples, cytology, FISH, and overall cyto\&FISH were diagnostic for malignancy in $18.6,30$, and $37.1 \%$, respectively. From 100 effusion samples, protein levels from matched serum specimens were available. Out of these 100 effusions, 60 were transudates, with a protein concentration as determined by effusion protein/serum protein quotient of $<0.5$; in these, cytology, FISH, and cyto\&FISH were diagnostic for malignancy in 35,40 , and $50 \%$, respectively.

\section{DISCUSSION}

In this study of patients with tumour-associated effusions, it was possible to determine the percentage of cases in whom the appearance of effusion was the first sign of primary disease or the first sign of relapse (Table 1). In the literature, information on the frequencies of effusion as the first sign of malignant disease or relapse is sparse. In our patients with invasive breast cancer, effusion was the first sign of relapse in $36 \%$ of cases. This finding is in line with results from a previously reported series (Raju and Kardinal, 1981). Of clinical relevance, the strong association between 'new effusion of unclear origin' and a potentially underlying tumour disease may urge performing further diagnostic steps, including analysis of effusions with molecular tools (see below).

To the best of our knowledge, this is the largest series of effusions in which conventional cytology and a molecular method such as FISH were compared for the detection of malignancy. We show that FISH analysis for the detection of tumour-associated aneuploidy is significantly more sensitive than routine cytology. In control effusions collected from patients with nonmalignant diseases, cutoffs were set for discriminating background signals from true aneuploidy, indicating the presence of tumour cells. With this reference, a sensitivity of at least $97 \%$ was achieved for FISH analysis. The diagnostic benefit of FISH was most evident in breast and lung cancer and in the group of gynaecologic malignancies. Cytology remains certainly the gold standard for the routine analysis of effusions. However, taking the positive results of cytology and FISH together (cyto\&FISH), the combination of both methods brought the highest diagnostic yield (Table 4). Overall, cyto\&FISH was clearly superior to cytology alone in breast, lung, and pancreatic cancer and in the categories of gynaecologic and gastrointestinal tumours. There was also a trend favouring cyto\&FISH in ovarian carcinoma. When compared to cytology, FISH analysis is often complementarily diagnostic and should be used as second diagnostic step in certain cases with negative or ambiguous cytology. This may be of clinical practice in patients with known or suspected cancer. We do not propose FISH or other laborious molecular techniques as first-line diagnostic tools in all effusion samples submitted to analysis, due to a low pre-test probability of detecting malignant cells in many cases and costs.

Transudates are considered to be tumour cell contaminated in $\leq 5 \%$ of cases (Ashchi et al, 1998). Notably, cytology and FISH enabled us to detect tumour cells even in a significant proportion of transudates as defined by protein concentration and effusion/ serum protein ratio. There has been intensive debate in the literature over whether or not effusions classified as transudates need any further diagnostic evaluation (Ashchi et al, 1998; Castro et al, 1998; Moltyaner et al, 2000). Our data support the view that, as is the case with exsudates, cytologic and molecular evaluation is warranted in transudates as well. 


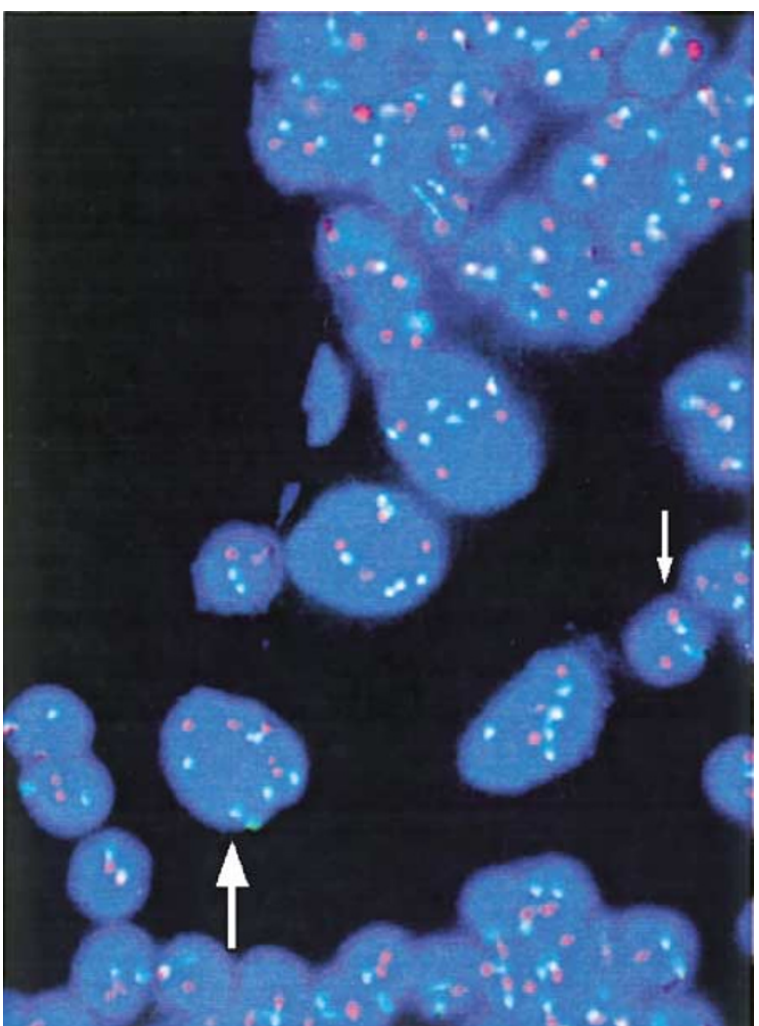

Figure I Detection of numerical chromosomal anomalies in pleural effusion cells from a patient with advanced non-small-cell lung cancer. Within a dense reactive cellular background, at least four tumour cells with marked aneuploidy can be recognised. A tumour cell with six copies of chromosome II (green) and four copies of chromosome 17 (orange) is marked by the large arrow. As internal control, the leukocyte (small arrow) exhibits a $2 / 2$ signal pattern.

Fluorescence in situ hybridisation analysis represents only one of the molecular examinations capable of detecting malignant cells dispersed in effusions. Others are reverse-transcriptase-polymer- ase chain reaction and single-nucleotide polymorphism (SNP) analysis (Yang et al, 1998; Chang et al, 2002; Grünewald et al, 2002). The big advantage of FISH is the direct visualisation of tumour cells exhibiting numeric chromosomal aberrations (Figure 1). The diagnostic power of FISH may be further improved in two ways: first, if the primary tumour is FISH-genotyped with a panel of FISH probes for different chromosomes as part of the initial diagnostic work-up, the probe(s) best suited to indicate tumour-associated aneusomy in an individual case can be chosen to sensitively detect tumour cell involvement in effusions taken subsequently. With this procedure, we and others were able to show by FISH that primary tumours and synchronous or metachronous locoregional or distant metastases exhibit nearly identical patterns of numeric chromosomal aberrations (Simpson et al, 1996; Fiegl et al, 2000; Fehm et al, 2002). Second, enrichment steps like flow cytometry or immunobead selection can be applied prior to FISH analysis in order to deplete the reactive cellular background (Feuring-Buske et al, 1999; Sakaguchi et al, 1999).

Diagnosis of malignant cells in effusions or other body fluids such as lavages, urine, and cerebrospinal fluid is essential for adequate staging and prognostic evaluation. For example, in lung cancer the absence or presence of malignant cells in pleural effusions discriminates limited (e.g., T1) from locally advanced stages (e.g., T4), with very different consequences for therapeutic management. It could be decisive, before a planned resection of lung cancer, to analyse by cytology and FISH an accompanying effusion or a pleural lavage (Buhr et al, 1997). Improved detection of pleural metastasis by 'molecular upstaging' could prevent patients with more extensive disease from undergoing surgery. We demonstrated in this study that FISH can be most useful for staging procedures in patients with cytologically negative or unclear effusions. However, conventional cytology in effusions is to date the only method accepted in the classical UICC/AJCC TNM classification (Hermanek et al, 1999). Confirmatory prospective studies are required to demonstrate the clinical benefit of molecular methods to detect disseminated tumour cells in terms of disease outcome. Based on our experience, we believe that molecular diagnostics such as FISH will become indispensable in initial diagnosis for the diagnostic workup of primary tumour tissue and other materials (e.g., pleural lavage, bone marrow), and for restaging during the course of malignant disease.

\section{REFERENCES}

Ashchi M, Golish J, Eng P, O’Donovan P (1998) Transudative malignant pleural effusions: prevalence and mechanisms. South Med J 91: 23-26

Buhr J, Berghauser KH, Gonner S, Kelm C, Burkhardt EA, Padberg WM (1997) The prognostic significance of tumour cell detection in intraoperative pleural lavage and lung tissue cultures for patients with lung cancer. $J$ Thorac Cardiovasc Surg 113: 683-690

Byrne AT, Ross L, Holash J, Nakanishi M, Hu L, Hofmann JI, Yancopoulos GD, Jaffe RB. (2003) Vascular endothelial growth factor-trap decreases tumour burden, inhibits ascites, and causes dramatic vascular remodeling in an ovarian cancer model. Clin Cancer Res 9: 5721-5728

Cajulis RS, Haines III GK, Frias-Hidvegi D, McVary K (1994) Interphase cytogenetics as an adjunct in the cytodiagnosis of urinary bladder carcinoma. A comparative study of cytology, flow cytometry and interphase cytogenetics in bladder washes. Anal Quant Cytol Histol 16: $1-10$

Castro DJ, Nuevo GD, Perez-Rodriguez E (1998) Cytologically proved malignant pleural effusions. Chest 114: 1798

Chang HW, Ali SZ, Cho SK, Kurman RJ, Shih IeM (2002) Detection of allelic imbalance in ascitic supernatant by digital single nucleotide polymorphism analysis. Clin Cancer Res 8: 2580-2585

Chen Z, Wang DD, Peier A, Stone JF, Sandberg AA (1995) FISH in the evaluation of pleural and ascitic fluid. Cancer Genet Cytogenet 84: $116-119$
Chhieng DC, Ko EC, Yee HT, Shultz JJ, Dorvault CC, Eltoum IA (2001) Malignant pleural effusions due to small-cell lung carcinoma: a cytologic and immunocytochemical study. Diagn Cytopathol 25: $356-360$

Drach J, Angerler J, Schuster J, Rothermundt C, Thalhammer R, Haas OA, Jäger U, Fiegl M, Geissler K, Ludwig H, Huber H (1995) Interphase fluorescence in situ hybridization identifies chromosomal abnormalities in plasma cells from patients with monoclonal gammopathy of undetermined significance. Blood 86: 3915-3921

Dwyer AJ (1991) Matchmaking and McNemar in the comparison of diagnostic modalities. Radiology 178: $328-330$

Eastmond DA, Schuler M, Rupa DS (1995) Advantages and limitations of using fluorescence in situ hybridization for the detection of aneuploidy in interphase human cells. Mutat Res 348: 153-162

Fehm T, Sagalowsky A, Clifford E, Beitsch P, Saboorian H, Euhus D, Meng S, Morrison L, Tucker T, Lane N, Ghadimi BM, Heselmeyer-Haddad K, Ried T, Rao C, Uhr J (2002) Cytogenetic evidence that circulating epithelial cells in patients with carcinoma are malignant. Clin Cancer Res 8: $2073-2084$

Feuring-Buske M, Haase D, Buske C, Hiddemann W, Wormann B (1999) Clonal chromosomal abnormalities in the stem cell compartment of patients with acute myeloid leukemia in morphological complete remission. Leukemia 13: 386-392 
Fiegl M, Haun M, Massoner A, Krugmann J, Müller-Holzer E, Hack R, Hilbe W, Marth C, Duba HC, Gastl G, Grünewald K (2004) Combination of cytology, fluorescence in situ hybridisation for aneuploidy, and reversetranscriptase polymerase chain reaction for human mammaglobin/ mammaglobin B improves diagnosis of malignant effusions. J Clin Oncol 22: $474-483$

Fiegl M, Kaufmann H, Zojer N, Schuster R, Wiener H, Mullauer L, Roka S, Huber H, Drach J (2000) Malignant cell detection by fluorescence in situ hybridization (FISH) in effusions from patients with carcinoma. Hum Pathol 31: $448-455$

Fiegl M, Massoner A, Steurer M, Krugmann J, Hack R, Grünewald K, Duba HC (2003) Improving tumor cell detection in pleural effusions by interphase cytogenetics. Cytometry 55B: 60-62

Fiegl M, Zojer N, Kaufmann H, Müllauer L, Schuster R, Huber H, Drach J (1999) Hyperdiploidy and apparent aneusomy in mesothelial cells from non-malignant effusions as detected by fluorescence in situ hybridization (FISH). Cytometry (Comm Clin Cytometry) 38: 15-23

Grünewald K, Haun M, Fiegl M, Urbanek M, Muller-Holzner E, Massoner A, Riha K, Propst A, Marth C, Gastl G (2002) Mammaglobin expression in gynecologic malignancies and malignant effusions detected by nested reverse transcriptase-polymerase chain reaction. Lab Invest 82: 1147 1153

Guzman J, Bross KJ, Scholmerich J, Freudenberg N, Costabel U (1992) Immunocytochemical analysis of ascitic fluid due to cirrhosis. A contribution to understanding the origin of markedly atypical cells. Acta Cytol 36: $236-240$

Hermanek P, Hutter RV, Sobin LH, Wittekind C (1999) International Union Against Cancer. Classification of isolated tumour cells and micrometastasis. Cancer 86: $2668-2673$

Ichikawa D, Hashimoto N, Hoshima M, Yamaguchi T, Sawai K, Nakamura Y, Takahashi T, Abe T, Inazawa J (1996) Analysis of numerical aberrations of specific chromosomes by fluorescent in situ hybridization as a diagnostic tool in breast cancer. Cancer 77: 2064-2069

Kibbelaar RE, Kok F, Dreef EJ, Kleiverda JK, Cornelisse CJ, Raap AK, Kluin PM (1993) Statistical methods in interphase cytogenetics: an experimental approach. Cytometry 14: 716-724

Koss LG (1992) Diagnostic Cytology and its Histopathologic Bases, pp 118 147, 878 -910, Philadelphia: Lippincott
Kutty CP, Remeniuk E, Varkey B (1981) Malignant-appearing cells in pleural effusion due to pancreatitis: case report and literature review. Acta Cytol 25: $412-416$

Light RW (2002) Clinical practice: pleural effusion. $N$ Engl J Med 346: $1971-1977$

Mian C, Bancher D, Kohlberger P, Kainz C, Haitel A, Czerwenka K, Stani J, Breitenecker G, Wiener H (1999) Fluorescence in situ hybridization in cervical smears: detection of numerical aberrations of chromosomes 7, 3, and X and relationship to HPV infection. Gynecol Oncol 5: 41-46

Moltyaner Y, Miletin MS, Grossman RF (2000) Transudative pleural effusions: false reassurance against malignancy. Chest 118: 885

Raju RN, Kardinal CG (1981) Pleural effusion in breast carcinoma: analysis of 122 cases. Cancer 48: $2524-2527$

Runyon BA (1994) Care of patients with ascites. N Engl J Med 330: 337-342

Runyon BA, Montano AA, Akriviadis EA, Antillon MR, Irving MA, McHutchison JG (1992) The serum-ascites albumin gradient is superior to the exudate - transudate concept in the differential diagnosis of ascites. Ann Intern Med 117: 215-220

Sakaguchi M, Virmani AK, Ashfaq R, Rogers TE, Rathi A, Liu Y, Kodagoda D, Cunningham HT, Gazdar AF (1999) Development of a sensitive, specific reverse transcriptase polymerase chain reaction-based assay for epithelial tumour cells in effusions. Br J Cancer 79: 416-422

Schenk T, Ackermann J, Brunner C, Schenk P, Zojer N, Roka S, Drach J (1997) Detection of chromosomal aneuploidy by interphase fluorescence in situ hybridization in bronchoscopically gained cells from lung cancer patients. Chest 111: 1691-1696

Sears D, Hajdu SI (1987) The cytologic diagnosis of malignant neoplasms in pleural and peritoneal effusions. Acta Cytol 31: 85-97

Simpson JF, Quan DE, Ho JP, Slovak ML (1996) Genetic heterogeneity of primary and metastatic breast carcinoma defined by fluorescence in situ hybridization. Am J Pathol 149: $751-758$

TNM classification of malignant tumours (1997) 5th edn. New York: John Wiley \& Sons

van Oostenbrugge RJ, Hopman AH, Arends JW, Ramaekers FC, Twijnstra A (2000) Treatment of leptomeningeal metastases evaluated by interphase cytogenetics. J Clin Oncol 18: 2053-2058

Yang CT, Lee MH, Lan RS, Chen JK (1998) Telomerase activity in pleural effusions: diagnostic significance. J Clin Oncol 16: 567-573 